\title{
Research on Parameters Influencing Dynamic Characteristic of Electromagnetic Actuator
}

\author{
Yong $\mathrm{Shi}^{\mathrm{a}}$, Yigao $\mathrm{Ni}^{\mathrm{b}}$ \\ College of Power and Energy Engineering, \\ Harbin Engineering University, \\ Harbin 150001, China \\ a sy_hit@163.com, 'bniyigao@hrbeu.edu.cn
}

\begin{abstract}
Electromagnetic actuators have been widely used in diesel engines, and its dynamic characteristics seriously affect the working performance of controlled objects. The research about the effect of structure parameters of electromagnetic actuators acting on its dynamic characteristics are introduced in many papers, but the effects of the number of coils and the control circuit are rarely studied. Therefore, in this paper, the dynamic model of the electromagnetic actuator for diesel engines is established and calibrated with experimental data. The affects of parameters such as the number of windings, the reset spring, and control circuit acting on dynamic characteristics of electromagnetic actuator are analyzed. Those research results can help to optimize the design of electromagnetic actuators.
\end{abstract}

Keywords-electromagnetic Actuator, influencing parameters, dynamic characteristic, simulation

\section{INTRODUCTION}

Electromagnetic actuators have been widely used in diesel engines, such as speed electromagnetic actuators which are used in position control of mechanical pump in electronic controlled diesel engines[1], high speed solenoid valves and flow control valves which are used to control the injection timing of fuel and cycle injection quantity of high pressure oil pump respectively in the common rail fuel system of diesel engines[2], electromagnetic actuators are used for the control of mechanical vibration in diesel engines, etc..The dynamic and static characteristics of electromagnet actuators seriously affect the control result of controlled devices, and the static characteristics and dynamic characteristics of electromagnetic actuators are closely related. In most cases, the dynamic characteristics of electromagnetic actuators are paid more attention in order to get a good control result. Therefore, many scholars had done much research on the impact of parameters on the dynamic characteristics of electromagnetic actuators. Such as Tao Zhijian analyzed the effect of parameters such as driving voltage, pre-tightening force, coil resistance and turns acting onthe response characteristics of anelectromagnetic gas valve[3].Zhang Yuanchang analyzedthe dynamic characteristics of a solenoid valve under the different parameters of inlet cavity size, the main valve spring stiffness, and dynamic damping hole size when the valve is power off[4]. Xu Haicheng discussed electromagnetic force of a flow control solenoid valve at the different coil window size and location, material and thickness of armature[5]].Moreover, in literature[6-8], the modeling and dynamic characteristicsof electromagnetic actuators were also analyzed.

Dynamic analysis on electromagnetic actuators has done much, but the research about the effects of the control circuit and the number of coil is done rarely. In this paper, the model of an electromagnetic actuator fordiesel enginesis built and calibrated, and the influence of single, double coil, and the control circuit to the dynamic characteristics of the electromagnetic actuator are researched.

\section{The StRUCTURE AND PRINCIPLE OF ELECTROMAGNETIC ACTUATOR}

The electromagnetic actuator for diesel engine speed governingis the drive mechanismof oil pump in anelectronically controlled diesel engine. The actuator can transform control signal to mechanical motion and drive rack to move straightly, and adjust the injection quantity of oil pump, which adapts to thechanges of speed and load of the controlled diesel engine. The basic structure of the electromagnetic actuator is as shown in Fig.1.

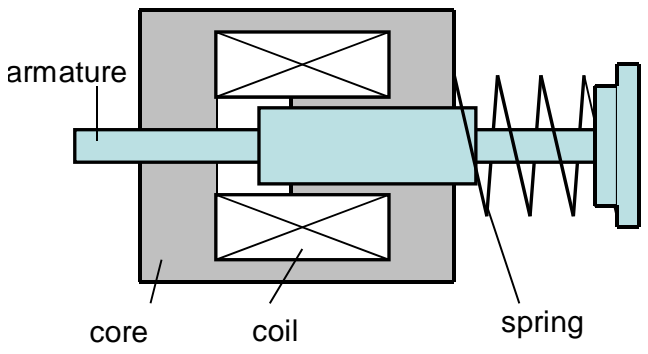

Figure 1. Structure of the actuator

According to the structure and principle of the electromagnetic actuator, the multi-physics simulation model is established using Ansoft software. The magnetic field finite element model of electromagnetic actuator is created in the Ansoft/Maxwell environment, and in Fig.2, magnetic field distribution of the electromagnetic actuator under the condition of $24 \mathrm{~V}$ voltage and the maximum stroke is shown, which do not reach saturate. The mechanical motion and circuit control model of electromagnetic actuator is established in the Ansoft/Simplore environment, and the model is shown in 
Fig.3. The control circuit is consistent with the actual testing circuit. Using the co-simulation of Maxwell and Simplore software, dynamic characteristics of the electromagnetic actuator are analyzed.

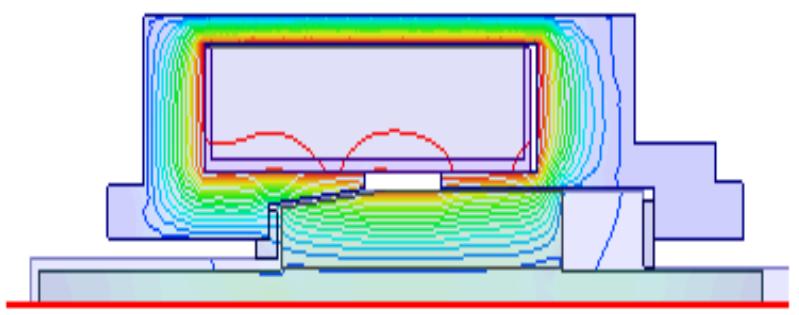

Figure 2. The actuator magnetic distribution map



Figure 3. Mechanical motion and control circuit diagram

\section{PARAMETERS IDENTIFICATION OF SIMULATION MODEL}

\section{A. Dynamic response time measurement}

In order to ensure the accuracy of the simulation results, the model need be calibrated. So the experiments and data acquisition device of the actuator were established as shown in Fig.4.The electromagnetic actuator was turned on and off suddenly to $24 \mathrm{~V}$ voltage, and to measure the displacement of the actuator. Meanwhile, a sampling resistance $0.1 \Omega$ was connect in the test circuit in series, and its current was measured.

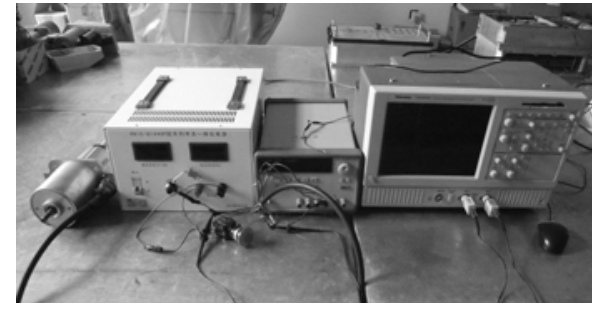

Figure 4. Measurement and data acquisition device

Fig. 5 and Fig. 6 are the dynamic response curves of the actuator when $24 \mathrm{~V}$ voltage was suddenly truned on and off, respectively. In the Figs, the upper curve is the change of current, and the lower curve is the change of armature position. By measuring the interval time between the moment that current begins to change and the moment that armature reaches the maximum stroke, the dynamic response time is $130 \mathrm{~ms}$ when $24 \mathrm{~V}$ voltage was suddenly turned on. Similarly, By measuring the interval time between the moment that the current begins to change and the moment that armature returns its original position, the dynamic response time is $56.4 \mathrm{~ms}$ when $24 \mathrm{~V}$ voltage was suddenly turned off.

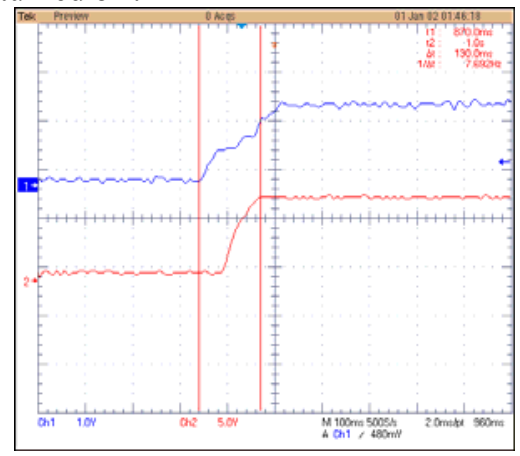

Figure 5. Dynamic response voltage curve of loading $24 \mathrm{~V}$



Figure 6. Dynamic response curve of unloading 24V voltage

According to the structure and parameters of the actuator, initial parameters are setup and simulated. The experimental dynamic response curves are used to modify the simulation model. When the model parameters are as shown in Table.1, the simulation curves are as shown in Fig. 7.

TABle 1 The PARAmeters OF THE ACtuator

\begin{tabular}{l|l}
\hline parameters & value \\
\hline spring stiffness $(\mathrm{N} / \mathrm{m})$ & 3550 \\
\hline pre-tightening force $(\mathrm{N})$ & 84 \\
\hline strike of armature $(\mathrm{mm})$ & $0-20$ \\
\hline mass of armature $(\mathrm{kg})$ & 0.8 \\
\hline turns of Coill & 605 \\
\hline resistance of Coill $(\Omega)$ & 2.9 \\
\hline turns of Coil 2 & 585 \\
\hline resistance of Coil $2(\Omega)$ & 2.9 \\
\hline
\end{tabular}




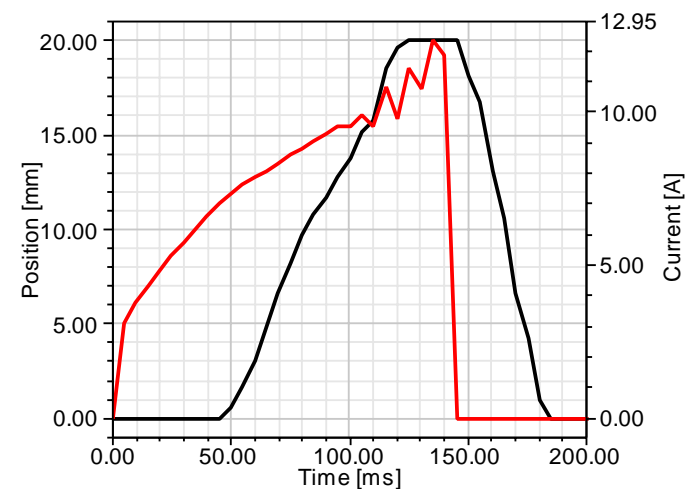

Figure 7. Dynamic response simulation curve

From the Fig7, it can be gotten that the dynamic response time is $125 \mathrm{~ms}$ when $24 \mathrm{~V}$ voltage is on suddenly, the dynamic response time is $52 \mathrm{~ms}$ when $24 \mathrm{~V}$ voltage is off suddenly. Compared with the experimental data, the error of the dynamic response times is within $8 \%$, so, the model can be used for analysis.

\section{ANALYSIS OF DYNAMIC RESPONSE CHARACTERISTICS}

\section{A. Effects of pre-tightening force and stiffness of spring}

We can know from the mechanical motion equation, the pre-tightening force of the spring has two impacts on dynamic response characteristics of the actuator. When the pre-tightening force and spring stiffness are increased, the resistance force is increased, and the response time is longer while the $24 \mathrm{~V}$ voltage is suddenly acted. The response time is shorter while the $24 \mathrm{~V}$ voltage is suddenly turned off, because the reset force is increased.

Fig. 8 shows the response curves of $60 \mathrm{~N}, 80 \mathrm{~N}$ and $100 \mathrm{~N}$ pre-tightening force when $24 \mathrm{~V}$ voltage is suddenly turned on and off. When $24 \mathrm{~V}$ voltage is suddenly turned on, the response times are 115,125 and $130 \mathrm{~ms}$, respectively. When $24 \mathrm{~V}$ voltage is suddenly turned off, the response times were 60,52 and $48 \mathrm{~ms}$. Fig.9 shows the response curves of $3000 \mathrm{~N} / \mathrm{m}, 3500 \mathrm{~N} / \mathrm{m}$ and $4000 \mathrm{~N} / \mathrm{m}$ spring stiffness, when $24 \mathrm{~V}$ voltage is suddenly turned on and off.

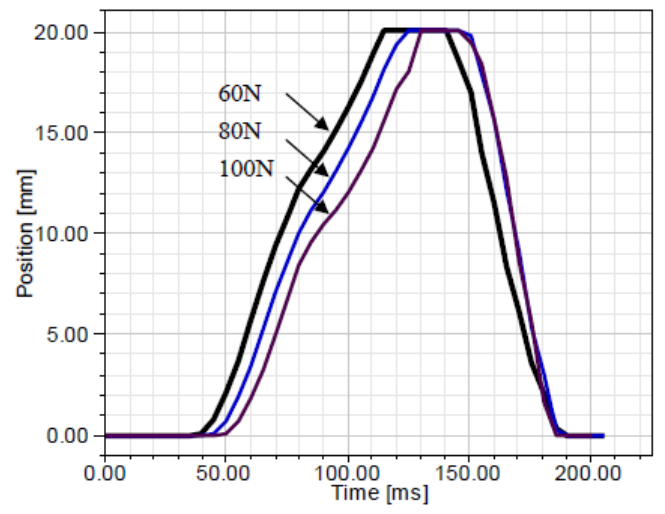

Figure 8. Response curve of different pre-tightening force of spring

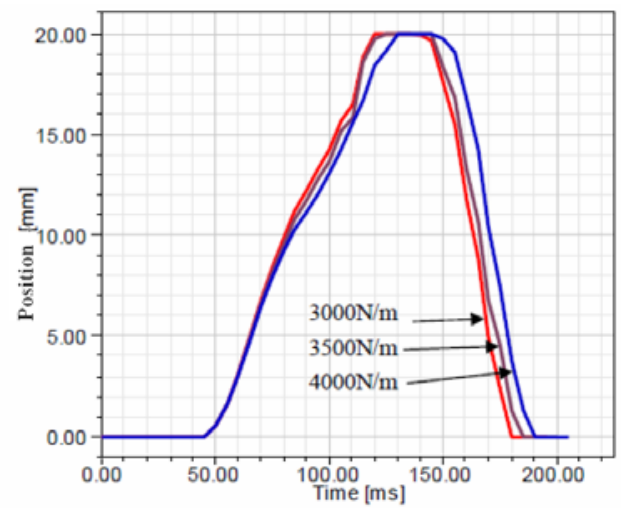

Figure 9. Response curve of different stiffness of spring

When $24 \mathrm{~V}$ voltage is suddenly turned on, the response times are 120,125 and $130 \mathrm{~ms}$, respectively. When $24 \mathrm{~V}$ voltage is suddenly turned off, response times are 50, 49 and $48.5 \mathrm{~ms}$, respectively. From the simulation results, when the reset spring stiffness changes from $3000 \mathrm{~N} / \mathrm{m}$ to $4000 \mathrm{~N} / \mathrm{m}$, the two response times have little error. It is because that, when spring stiffness is changed, the energy consumption is as follow.

$$
J=\int_{t_{0}}^{t_{1}} \Delta K x(t) d t
$$

There: $\Delta K$ - stiffness variation;

$x(t)$-displacement change function;

$t_{0}, t_{1}$-start time and end time of motion, respectively.

The response time of $24 \mathrm{~V}$ voltage sudden acting is far greater than the response time of $24 \mathrm{~V}$ voltage sudden turning off, so in the process of the $24 \mathrm{~V}$ voltage sudden acting, the energy consumption of the stiffness variation is greater than it does in the process of $24 \mathrm{~V}$ voltage sudden turning off.

In addition, the pre-tightening force and spring stiffness will seriously affect the static characteristics, so in the actual, it is very difficult to only optimize the reset spring to satisfy the static characteristics and response time.

\section{B. Effects of single anddouble coils}

The electromagnetic actuator uses dual-coil. In order to study the response times of single coil and double coils, changes the coil of the model from double coils to single coil. The turn number of the single coil is set 1185 as the dual-coil, and the resistance is set according to two cases, $2.9 \Omega$ and $5.8 \Omega$. The simulation results are shown in Fig. 10, the left curve is for resistance $2.9 \Omega$, and the right curve is for $5.8 \Omega$. 




Figure 10. Response curve of single coil with different resistance

When the resistance is $2.9 \Omega$, response time of $24 \mathrm{~V}$ voltage sudden turning on is $185 \mathrm{~ms}$, and response time of $24 \mathrm{~V}$ voltage sudden turning off is $55 \mathrm{~ms}$. when the resistance is $5.8 \Omega$, response time of $24 \mathrm{~V}$ voltage suddenly turning on is $280 \mathrm{~ms}$, and response time of $24 \mathrm{~V}$ voltage suddenly turning off is $52 \mathrm{~ms}$. Therefore, the dynamic response of single coil is longer than double coils.

In actual, if the same wire is used, with the same number of turns, the resistance of single coil is 2 times the double coils. Therefore, if the voltage source is used to control actuators, double coils have a better response time than single coil.

\section{Control circuit}

Mutation of the coil current will produce a reversal electromotive force. In order to protect the driver transistor, a freewheeling diode is needed to connect to the coil circuit in series, as shown in Fig.3.

In order to study the influence of the freewheeling diode on the dynamic characteristics of the actuators, the freewheeling diode is serially connected with a resistor R2, and its resistance is set to 0 and 6 . The dynamic response curves of the actuator at $24 \mathrm{~V}$ voltage suddenly turning on and off are as shown in Fig. 11.

From Fig.11, there are no effects on the dynamic response time in the opening process, but at the $24 \mathrm{~V}$ voltage suddenly turning off, the response time is $52 \mathrm{~ms}$ (as shown in Fig.2) when there is not freewheeling diode in the control circuit. With the freewheeling diode in the control circuit, when $\mathrm{R} 2=0 \Omega$, the response time is $85 \mathrm{~ms}$, and when $\mathrm{R} 2=6 \Omega$, the response time is $55 \mathrm{~ms}$. Of course, it is because the reverse current is consumed by the resistance, and the response time is shorter.

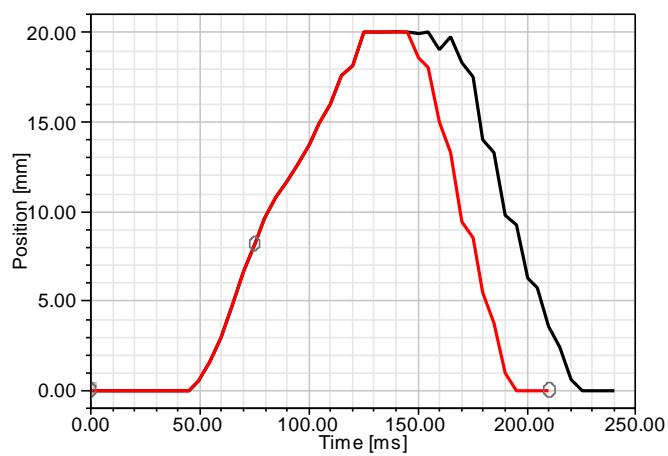

Figure 11. Different system dynamic response time curve of flow resistance

\section{SUMMARY}

In this paper, Simplorer and Maxwell are used to build the co-simulation platform of the dynamic model of an electromagnetic actuator. The influence of parameters on dynamic characteristics of the actuator is analyzed, and gets the following conclusion:

(1) Because the dynamic response time in open process is larger than in the closing process, the spring parameters of stiffness and pre-tightening force have more severe effect on dynamic response time of the actuator in open process than in the closing process. The effects of stiffness and pre-tightening force on dynamic response time of the actuator are opposite to it in the closing process. Therefore, it can't simultaneously meet the requirement of reducing the response time of the actuator in the opening and closing process time with the way of only changing the two parameters.

(2) If controlled by voltage source parallel mode and with the same turns of winding, the resistance of multi-coil is less than that of single coil, and smaller inductance, so in opening process, the dynamic response time of multi-coil is far less than that of single coil, but in the closing process, there is not obvious different.

(3) There is a significant effect on the dynamic response time of the electromagnetic actuator in control circuit.In actual, a resistance is connect to freewheeling diode in serieswill effectively reduce the time of dynamic characteristics of actuator in closing process.

\section{ACKNOWLEDGMENTS}

Project supported by the National Natural Science Foundation of China (Grant No. 51475100) 


\section{REFERENCES}

[1] ZHANG LianYu, SHI Yong,GAO Mingchun, QI Zhida, Analysis and Researeh on The Dynamie Performane of Electromagnetic Actuator, J.of Engineering Thermo- physics , Vol 34, (2013), p.858-861

[2] Fan Li-yun,GAO Ming-chun, MA Xiu-zhen, Quantitative Analysis of Electromagnetie Force of High-Speed Solenoid Vavle for Electron-Controlled Unit Pump,Chinese internal combustion engine engineering, Vol 34, (2013), p33-40

[3] TAO Zhi-jian, WANG Yi-bai,LIU Yu,CHANG Heng, Simulation on Dynamic Response Characteristics of Electromagnetic Gas Valve,Computer Simulation, Vol 30 , (2013), p68-71

[4] ZHANG Yuan-shen,MA Zhong-xiao,NIU Xue-hong, SONG You-ming,ZHOU Xuan,Study on Dynamic Characteristics of Electromagnetic Relif Valve Based on AMESim, J. of Gansu Sciences. Vol 25 , (2002), p112- 115
[5] XU Hai-cheng,LI Yu-xue, OUYANG Guang-yao, Optimi- zation Design of Solenoid Valve for Electronically Controlled High Pressure Pump, Chinese internal combustion engine engineering, Vol 30, (2009), p48-51

[6] Maiti R, Saha R, Watton J, The static and dynamic characteristics of a pressure relief valve with a proportional solenoid-controlled pilot stage, Proceedings of the Institution of Mechanical Engineers, Part I: J. of Systems and Control Engineering, Vol 216, (2002),p143-156

[7] Thomas, R Benson,FEA based analysis of solenoid in automotive application with model development, International Journal of Materials and Structural Integrity, Vol 3, 2009, p 269-293

[8] Needham, D . L Holtz, A . J,Giles, D. K.,Modeling dynamic response of an actuator for individual nozzle control of agricultural spray flow rate and droplet size, Trans. of the ASABE, Vol $55,(2012), \mathrm{p} 371-377$ 